\title{
Innovation Research on the Professional Planning and its Training Mode about the Vocational Academy Students Based on the Human Oriented Perspective
}

\author{
Liu Xiaobing \\ Jiangxi V\&T College of Communications, Nanchang 330013, China
}

Keywords: Human oriented perspective, Vocational academy, Career planning, Linear regression, Multivariate variance.

\begin{abstract}
On the basis of analyzing the career planning theory, and combining with the career planning education problems in vocational college, this paper proposes a career planning and training model based on human oriented perspective, and investigates and statistically analyzes the career planning of vocational college students in this training mode. At the same time, this paper establishes the seven influence factor models of vocational college students' career planning, and the use of linear regression method carries out analysis on the influence factors. Taking gender and age as independent variables, the seven factors affect the career planning as the variables, to carry out the multivariate analysis of variance. The statistical analysis can be found that the influence of gender on career planning is not significant, and the influence of grade on career planning is great. In the course of vocational education, we should pay more attention to the education idea and the career planning education of graduating class, to improve students' career planning ability.
\end{abstract}

\section{Introduction}

In recent years, with the continuous expansion of vocational academy students, the number of vocational academy graduates is increasing, many graduates have to choose the jobs that don't want to accept in the face of the pressure, so that the level of employment and the students' satisfaction are lower [1-3]. In the choice of unsatisfactory work, students will gradually produce discontent with the status quo of work and life, so as to gradually become a negative factor affecting social and economic development. In order to avoid the development of this kind of bad phenomenon, it is necessary to carry out the career planning education for vocational academy students, so as to reduce the employment resistance, so that students can correctly understand the employment plight and grasp the employment structure [4,5]. Based on people-oriented, making the vocational academy students achieve the employment status of the scientific development and social harmony and progress.

\section{The Innovation of Career Planning Training Mode Based on Human Oriented Perspective}

Occupation. The concept of the occupation is no unified and clear statement, and many people have their own understanding on the occupation word, such as the United States Taylor believed that the occupation was an inherent model, and the model was associated with a number of groups with unique experience; Schulz believed that in order to maintain the individual living, the occupation can earn income, and engaged in social activities with the continuous and social value [6].

Occupation career. Occupation career has been proposed in the last century sixty years, and it was introduced into China from the ninety, however the definition of occupation career term has many differences in the academic community [7,8]. Different researchers described the occupation career definition from different perspectives, in which Holzer thought that occupation career definition is the use of lifetime pursuits with the career related activities; Slade and Roswell defined that in people's life, career was the organism associated with work, value view, attitude and so on; Redmond-ino will define career for people's life experience and moral education related activities, including position, jobs, tasks and so on. 
Career planning. Career planning is to achieve their career ideals, and many graduates set up their initiative and strive to achieve career goals for the development of action direction and time arrangement, at the same time to make a series of arrangements in order to achieve this goal.

The influence of career planning on the employment of students in higher vocational colleges. At present, many graduates have not done enough preparation in career academy because of the domestic employment market competition, so that they can not find a suitable social position after graduation, finding the job will result in a great pressure on the school, society and individuals under the lack of rational thinking.

The concept of people-oriented education. The concept of career planning education in vocational colleges based on people-oriented is mainly based on the students themselves, to explain the nature of learning from this point of view. As the basis of human nature education, we should be people's career choice, care for people's career development, the liberation of students' career choice thought as the highest pursuit, the development of students as the primary position.

\section{The Career Planning Linear Analysis Model in Vocational Colleges}

In the perspective of human oriented education, the career planning of vocational academy is mainly related to seven factors, and these seven factors include self evaluation, career planning knowledge, interpersonal communication, planning objectives, planning objective power, feedback adjustment and adaptation ability. Assuming that the career planning ability is $y$, these seven factors $x$ can be constructed by linear regression equation, and its expression is:

$y=a+b x$.

Among them, $a$ indicates the regression constant, $b$ indicates the regression coefficient, and then the regression equation is

$\hat{y}=b_{0}+b x$.

Residual equation is

$v_{i}=y_{t}-\hat{y}=y_{t}-b_{0}-b x_{t}, \quad t=1,2, \cdots, 7$.

Using the least square method, we can get the regression coefficient $b$ and $b_{0}$, its matrix form is:

$$
Y=\left(\begin{array}{c}
y_{1} \\
y_{2} \\
\vdots \\
y_{N}
\end{array}\right) \quad X=\left(\begin{array}{cc}
1 & x_{1} \\
1 & x_{2} \\
\vdots & \vdots \\
1 & x_{N}
\end{array}\right) \quad \hat{b}=\left(\begin{array}{l}
b_{0} \\
b
\end{array}\right) \quad V=\left(\begin{array}{c}
v_{1} \\
v_{2} \\
\vdots \\
v_{N}
\end{array}\right) .
$$

The matrix of the error equation is

$$
Y-X \hat{b}=V .
$$

In comparison $V=L-A \hat{X}$, hypothesis that $y_{i}$ accuracy is the same through the calculation, and there is

$$
\hat{b}=\left(X^{T} X\right)^{-1} X^{T} Y .
$$

The measured values are respectively substitution above formula, and it can be calculated.

$$
b=\frac{N \sum_{t=1}^{N} x_{t} y_{t}-\left(\sum_{t=1}^{N} x_{t}\right)\left(\sum_{t=1}^{N} y_{t}\right)}{N \sum_{t=1}^{N} x_{t}^{2}-\left(\sum_{t=1}^{N} x_{t}\right)^{2}}=\frac{l_{x y}}{l_{x x}} .
$$




$$
b_{0}=\frac{\left(\sum_{t=1}^{N} x_{t}^{2}\right)\left(\sum_{t=1}^{N} y_{t}\right)-\left(\sum_{t=1}^{N} x_{t}\right)\left(\sum_{t=1}^{N} x_{t} y_{t}\right)}{N \sum_{t=1}^{N} x_{t}^{2}-\left(\sum_{t=1}^{N} x_{t}\right)^{2}}=\bar{y}-b \bar{x} \text {. }
$$

Where

$$
\begin{aligned}
& \bar{x}=\frac{1}{N} \sum_{t=1}^{N} x_{t} \\
& \bar{y}=\frac{1}{N} \sum_{t=1}^{N} y_{t} \\
& l_{x x}=\sum_{t=1}^{N}\left(x_{t}-\bar{x}\right)^{2}=\sum_{t=1}^{N} x_{t}{ }^{2}-\frac{1}{N}\left(\sum_{t=1}^{N} x_{t}\right)^{2} \\
& l_{x y}=\sum_{t=1}^{N}\left(x_{t}-\bar{x}\right)\left(y_{t}-\bar{y}\right)=\sum_{t=1}^{N} x_{t} y_{t}-\frac{1}{N}\left(\sum_{t=1}^{N} x_{t}\right)\left(\sum_{t=1}^{N} y_{t}\right) \\
& l_{y y}=\sum_{t=1}^{N}\left(y_{t}-\bar{y}\right)^{2}=\sum_{t=1}^{N} y_{t}{ }^{2}-\frac{1}{N}\left(\sum_{t=1}^{N} y_{t}\right)^{2}
\end{aligned}
$$

The regression equation variance between the $\mathrm{N}$ occupational planning factors is

$$
S=\sum_{t=1}^{N}\left(y_{t}-\bar{y}\right)^{2}=l_{y y}, v_{S}=N-1 .
$$

The expression of the variance can also be written

$$
S=U+Q \text {. }
$$

Among them,

$$
\begin{aligned}
& U=\sum_{t=1}^{N}\left(y_{t}-\bar{y}\right)^{2}=b l_{x y}, v_{U}=1 . \\
& Q=\sum_{t=1}^{N}\left(y_{t}-\hat{y}_{t}\right)^{2}=l_{y y}-b l_{x y}, v_{Q}=N-2 .
\end{aligned}
$$

Among them, $U$ is the square sum of linear regression, and it mainly reflects the $y$ change caused by factor linear relationship; $Q$ is the square sum of the residual error, and it indicates that the other factors cause the $y$ change; the influence of occupation planning factor on $y$ is significantly determined by the size of $U$ and $Q$, in which $U$ the greater $U$ and the smaller $Q$, it indicates that linear relationship is more significant, and there is the greater the impact of factors. the expression of computational statistics $F$ is

$$
F=\frac{U / v_{U}}{Q / v_{Q}} .
$$

For the simple linear regression, there is

$$
F=\frac{U / 1}{Q /(N-2)} .
$$

Checking the $\mathrm{F}$ distribution list, the use of significant level and freedom degree can be the significant test. If $F>F_{0.10}(1, N-2)$, the linear regression of career planning is significant at the level of 0.01 ; if $F_{0.05}(1, N-2) \leq F<F_{0.10}(1, N-2)$, the linear regression of career planning is significant at the 
level of 0.05 ; if $F_{0.10}(1, N-2) \leq F<F_{0.05}(1, N-2)$, the linear regression of career planning is significant at the level of 0.1 ; if $F<F_{0.10}(1, N-2)$, the regression is not significant.

\section{Analysis of Vocational Academy Career Planning Under the Human Oriented Education Mode}

Using linear regression method, this paper studies the influence of career academy occupational planning status quo and factor through questionnaire survey and statistical analysis. Finally, the analysis table of the measurement is obtained by calculating, the results are shown in Table 1.

Table 1. Analysis of career planning gender difference results in career academy

\begin{tabular}{|c|c|c|c|c|c|}
\hline & \multicolumn{2}{|c|}{ Male } & \multicolumn{2}{c|}{ Female } & $T$ \\
\hline Factor variable & Average & $\begin{array}{c}\text { Standard } \\
\text { deviation }\end{array}$ & Average & $\begin{array}{c}\text { Standard } \\
\text { deviation }\end{array}$ & $T$ \\
\hline Self evaluation & 2.82 & 0.62 & 3.32 & 0.56 & $3.85^{* * *}$ \\
\hline Career planning knowledge & 2.93 & 0.51 & 1.85 & 0.62 & $-0.72^{*}$ \\
\hline Interpersonal communication & 3.01 & 0.53 & 2.22 & 0.55 & 0.22 \\
\hline Planning objective & 3.05 & 0.51 & 3.22 & 0.63 & 0.78 \\
\hline Planning objective power & 2.73 & 0.55 & 2.69 & 0.65 & $6.85^{* * * *}$ \\
\hline Feedback regulation & 2.85 & 0.42 & 2.78 & 0.66 & $4.25^{* * *}$ \\
\hline Adaptability & 2.99 & 0.47 & 2.22 & 0.67 & $2.22^{* *}$ \\
\hline
\end{tabular}

Note: * indicates less than 0.05 , ** indicates less than 0.01 , *** indicates less than $0.005, * * * *$ indicates less than 0.001 .

Table 1 shows that using gender as independent variables and influence career planning seven factors as a variable carry out the analysis of multivariate variance, and the results are shown in Table 1. it can be seen that gender has no significant on the effect of career planning, and the significance of male students are higher than female students in addition to the three factors of career planning knowledge, interpersonal communication and adaptive ability; on the self evaluation, the significance of female students are higher than male students; in other factors, the difference between male students and female students is not significant.

Table 2. Analysis of career planning age difference results in vocational college

\begin{tabular}{|c|c|c|c|c|c|c|c|}
\hline & \multicolumn{2}{|c|}{ First grade } & \multicolumn{2}{c|}{ Second grade } & \multicolumn{2}{c|}{ Third grade } & $F$ \\
\hline Factor variable & Average & $\begin{array}{c}\text { Standard } \\
\text { deviation }\end{array}$ & Average & $\begin{array}{c}\text { Standard } \\
\text { deviation }\end{array}$ & Average & $\begin{array}{c}\text { Standard } \\
\text { deviation }\end{array}$ & $F$ \\
\hline Self evaluation & 2.23 & 0.64 & 3.31 & 0.51 & 3.28 & 0.41 & $5.25^{* * *}$ \\
\hline $\begin{array}{c}\text { Career planning } \\
\text { knowledge }\end{array}$ & 2.12 & 0.58 & 1.89 & 0.62 & 2.13 & 0.48 & $5.58^{* * * *}$ \\
\hline $\begin{array}{c}\text { Interpersonal } \\
\text { communication }\end{array}$ & 3.33 & 0.51 & 2.21 & 0.51 & 3.12 & 0.52 & $4.32^{* * *}$ \\
\hline $\begin{array}{c}\text { Planning } \\
\text { objective }\end{array}$ & 3.28 & 0.53 & 2.22 & 0.68 & 2.12 & 0.49 & $5.65^{* * * *}$ \\
\hline $\begin{array}{c}\text { Planning } \\
\text { objective power }\end{array}$ & 2.31 & 0.56 & 3.33 & 0.61 & 2.23 & 0.46 & $5.07^{* * * *}$ \\
\hline $\begin{array}{c}\text { Feedback } \\
\text { regulation }\end{array}$ & 2.92 & 0.48 & 2.12 & 0.67 & 2.38 & 0.47 & $2.25^{* *}$ \\
\hline Adaptability & 2.25 & 0.42 & 2.23 & 0.62 & 3.22 & 0.49 & $6.96^{* * *}$ \\
\hline
\end{tabular}

Note: * indicates less than 0.05 , ** indicates less than 0.01 , *** indicates less than $0.005, * * * *$ indicates less than 0.001 . 
In Table 2, it can be seen that the career planning ability of vocational college students has been significantly improved from the first grade to three grade, but the majority of factors have a big difference, and the biggest difference is the graduation and other grades, the students career planning will be more prone to turbulence when they are more close to graduation. Therefore, the intensity of the professional planning education in career academy should be increased, we should be the full consideration of the people-oriented education concept, so that students adhere to the existing planning, improving the ability of vocational planning.

\section{Summary}

In view of the career planning education problems in vocational college, this paper put forwards a new career planning and training model based on human visual angle, and carries out the linear regression analysis of vocational college students' career planning influence factors under the training model. The results of calculation and analysis can be found that gender has no significant effect on career planning, and the significance of male students is higher than female in addition to the three factors of career planning knowledge, interpersonal communication and adaptive ability; however, the female students are significantly higher than male in self-evaluation. From the first grade to three grade, vocational college students' career planning ability has been significantly improved, the majority of factors have a big difference, so we should respect the individual differences of students in the career planning education, to achieve the people-oriented education of the professional planning based on people-oriented.

\section{References}

[1] Y.S. Li. Research on education classification and cultivation mode in Chinese college graduate. Hefei: Journal of Hefei university, 2013, 21(3): 64-65.

[2] Q.Y. Lou. The employment decisions of graduate career planning based on SWOT analysis. Higher agricultural education, 2014(8): 80-83.

[3] L.L. Sun. The research on graduate career planning. Chinese scientific and technological information, 2014(17): 161-162.

[4] X.Q. Wang. Theory and practice of higher mathematics stratified teaching mode. Jilin education, 2013(11): 20- 21.

[5] Z.Y. Sun, M. Dong. Analysis and countermeasures of college students' career planning based on attribution theory. Journal of Anyang college, 2014(3): 21-24.

[6] F.Y. Li. The application and thinking of multimedia in English teaching. China's information technology education, 2014(8): 43-44.

[7] L.Y. Song. The psychological characteristics of middle school students in English teaching. Educational exploration, 2011(3): 55-56.

[8] J. Song. English teaching should pay attention to the students' emotion. Chapter, 2013(5): 92-93. 